\title{
Article \\ Genetic and Phenotypic Landscape of PRPH2-Associated Retinal Dystrophy in Japan
}

\author{
Akio Oishi ${ }^{1,2, *,+}+\mathbb{D}$, Kaoru Fujinami ${ }^{3,4,5,+}$, Go Mawatari ${ }^{6}$, Nobuhisa Naoi ${ }^{6}$, Yasuhiro Ikeda ${ }^{6}$, Shinji Ueno ${ }^{7}$, \\ Kazuki Kuniyoshi ${ }^{8}$, Takaaki Hayashi ${ }^{9}$ D , Hiroyuki Kondo ${ }^{10}$, Atsushi Mizota ${ }^{11}$, Kei Shinoda 11,12 $\mathbb{D}$, \\ Sentaro Kusuhara ${ }^{13}$, Makoto Nakamura ${ }^{13}$, , Takeshi Iwata ${ }^{14}$, Akitaka Tsujikawa ${ }^{1(D)}$ \\ and Kazushige Tsunoda ${ }^{15}$ on behalf of Japan Eye Genetics Consortium Study Group
}

1 Department of Ophthalmology and Visual Sciences, Kyoto University Graduate School of Medicine, Kyoto 606-8507, Japan; tujikawa@kuhp.kyoto-u.ac.jp

2 Department of Ophthalmology and Visual Sciences, Nagasaki University, Nagasaki 852-8102, Japan

3 Laboratory of Visual Physiology, Division of Vision Research, National Institute of Sensory Organs, National Hospital Organization Tokyo Medical Center, Tokyo 152-8902, Japan; k.fujinami@ucl.ac.uk

4 Institute of Ophthalmology, University College London, London EC1V 9EL, UK

5 Department of Inherited Eye Disease, Moorfields Eye Hospital, London EC1V 2PD, UK

6 Department of Ophthalmology, Faculty of Medicine, University of Miyazaki, Miyazaki 889-1692, Japan; go_mawatari@med.miyazaki-u.ac.jp (G.M.); nobunaoi@gmail.com (N.N.); ymocl@med.miyazaki-u.ac.jp (Y.I.)

7 Department of Ophthalmology, Nagoya University Graduate School of Medicine, Nagoya 466-8550, Japan; ueno@med.nagoya-u.ac.jp

8 Department of Ophthalmology, Kindai University, Osaka 589-8511, Japan; kazuki@med.kindai.ac.jp

9 Department of Ophthalmology, The Jikei University School of Medicine, Tokyo 105-8461, Japan; taka@jikei.ac.jp

check for

updates

Citation: Oishi, A.; Fujinami, K.; Mawatari, G.; Naoi, N.; Ikeda, Y.; Ueno, S.; Kuniyoshi, K.; Hayashi, T.; Kondo, H.; Mizota, A.; et al. Genetic and Phenotypic Landscape of PRPH2-Associated Retinal Dystrophy in Japan. Genes 2021, 12, 1817. https://doi.org/10.3390/genes12111817

Academic Editor: Jean-Michel Rozet

Received: 22 October 2021

Accepted: 17 November 2021

Published: 18 November 2021

Publisher's Note: MDPI stays neutral with regard to jurisdictional claims in published maps and institutional affiliations.

Copyright: (c) 2021 by the authors. Licensee MDPI, Basel, Switzerland. This article is an open access article distributed under the terms and conditions of the Creative Commons Attribution (CC BY) license (https:/ / creativecommons.org/licenses/by/ $4.0 /)$.
10 Department of Ophthalmology, University of Occupational and Environmental Health, Kitakyushu 807-8555, Japan; kondohi@med.uoeh-u.ac.jp

11 Department of Ophthalmology, Teikyo University, Tokyo 173-8605, Japan; mizota-a@med.teikyo-u.ac.jp (A.M.); shinodak@med.teikyo-u.ac.jp (K.S.)

12 Department of Ophthalmology, Saitama Medical University, Moroyama 350-0495, Japan

13 Department of Surgery, Division of Ophthalmology, Kobe University Graduate School of Medicine, Kobe 650-0017, Japan; kusu@med.kobe-u.ac.jp (S.K.); manakamu@med.kobe-u.ac.jp (M.N.)

14 Division of Molecular and Cellular Biology, National Institute of Sensory Organs, National Hospital Organization Tokyo Medical Center, Tokyo 152-8902, Japan; takeshi.iwata@kankakuki.go.jp

15 Division of Vision Research, National Institute of Sensory Organs, National Hospital Organization Tokyo Medical Center, Tokyo 152-8902, Japan; tsunodakazushige@kankakuki.go.jp

* Correspondence: akio.oishi@nagasaki-u.ac.jp; Tel.: +81-95-819-7345

+ Joint first authors.

Abstract: Peripherin-2 (PRPH2) is one of the causative genes of inherited retinal dystrophy. While the gene is relatively common in Caucasians, reports from Asian ethnicities are limited. In the present study, we report 40 Japanese patients from 30 families with PRPH2-associated retinal dystrophy. We identified 17 distinct pathogenic or likely pathogenic variants using next-generation sequencing. Variants p.R142W and p.V200E were relatively common in the cohort. The age of onset was generally in the 40's; however, some patients had earlier onset (age: 5 years). Visual acuity of the patients ranged from hand motion to 1.5 (Snellen equivalent 20/13). The patients showed variable phenotypes such as retinitis pigmentosa, cone-rod dystrophy, and macular dystrophy. Additionally, intrafamilial phenotypic variability was observed. Choroidal neovascularization was observed in three eyes of two patients with retinitis pigmentosa. The results demonstrate the genotypic and phenotypic variations of the disease in the Asian cohort.

Keywords: retinitis pigmentosa; cone-rod dystrophy; macular dystrophy; peripherin 2 (PRPH2); retinal degeneration slow (RDS) 


\section{Introduction}

Inherited retinal dystrophy (IRD) refers to a group of diseases characterized by progressive retinal cell death, particularly photoreceptor cell death, caused by genetic mutations. More than 300 causative genes have been reported to date, with a considerable overlap [1]. Recently, gene therapy has become available to patients with pathogenic variants of a specific gene, and other trials are ongoing [2]. Thus, identifying causative genes is becoming increasingly important.

Peripherin-2 (PRPH2; online Mendelian inheritance in man ID: 179605, https:/ / www. omim.org/ accessed on 17 November 2021) is one of the causative genes of IRD. The gene is located on chromosome 6p21.2 and contains three exons. The gene was also called retinal degeneration slow (RDS) because the ortholog was found in a classic animal model, rds mice [3]. PRPH2 encodes PRPH2 protein, which consists of 346 amino acids and is essential for the proper outer segment formation and maintenance of outer segment disc alignment, both in rod and cone photoreceptors [4]. The gene is generally associated with an autosomal-dominant inheritance pattern, but autosomal recessive [5] and digenic patterns in conjunction with retinal outer segment membrane protein 1 (ROM1) has also been reported [6,7]. Pathogenic variants of PRPH2 may cause diverse phenotypes such as retinitis pigmentosa (RP), retinitis punctata albescens, cone/cone-rod dystrophy (CRD), and macular dystrophies (MD) [3,8-10]. Variable phenotypes were observed in a single family sharing the same variant [11-13]. The presence of ROM1 variants may modify these phenotypic appearances [14] or increase the severity of the disease [15].

Pathogenic variants of PRPH2 are one of the major causes of IRD. It has been reported that $5.2 \%$ of patients with IRD are associated with PRPH2 in the United Kingdom [13] and $3.9 \%$ of patients with RP are associated with PRPH2 in Spain [16]. The prevalence is particularly high in patients with autosomal dominant CRD or MD; $12 \%$ in CRD/MD [17], $19.5 \%$ in autosomal dominant CRD/MD [18], and 10.3\% in autosomal dominant RP were associated with $P R P H 2$ [19], respectively.

Meanwhile, the prevalence of $P R P H 2$ as a causative gene of IRD in Asian populations is relatively low. The prevalence of PRPH2 as a causative gene of RP is $0.06 \%$ in China [20], $1.6 \%$ in Korea [21], and 0-3.4\% in Japan [22-24]. Moreover, the prevalence of PRPH2 as a causative gene of CRD or MD is $2.3-6.1 \%$ [25,26]. Thus, little is known about the genetic and phenotypic spectrum of PRPH2-associated IRD in Asia.

In this multicenter joint study, we recruited patients with $P R P H 2$-associated IRD from all over Japan and reported their phenotypic and genotypic characteristics.

\section{Materials and Methods}

This study adhered to the tenets of the Declaration of Helsinki and was approved by the Ethics Committees of the participating institutions in Japan (National Institute of Sensory Organs, National Hospital Organization Tokyo Medical Center [Reference: R18029] and Kyoto University Graduate School of Medicine [Reference: G0746]). All patients who participated in the study provided written informed consent.

\subsection{Clinical Examinations}

All patients underwent comprehensive ophthalmological examination, including best-corrected visual acuity (BCVA) measurement, slit-lamp ophthalmoscopy, fundus photography, fundus autofluorescence imaging, optical coherence tomography (OCT), visual field test, electroretinogram (ERG), and electrooculogram (EOG), if available. ERG and EOG were recorded in accordance with the standards of the International Society for Clinical Electrophysiology of Vision [27-29]. Clinical diagnosis was made at each institution and reviewed by the consortium. In the present study, phenotype subgroups were defined based on clinical manifestations reported in a previous study. RP was defined as a progressive retinal dystrophy initially often presenting peripheral atrophy with generalized rod dysfunction greater than cone dysfunction. CRD was defined as a progressive retinal dystrophy initially often presenting macular atrophy with generalized 
cone dysfunction greater than rod dysfunction. MD was defined as a progressive retinal dystrophy presenting macular atrophy with confined macular dysfunction despite no abnormalities of generalized cone and rod functions [30].

In addition to the phenotype subgroups, we investigated the presence of clinical factors such as macular atrophy, peripheral atrophy, Best disease-like deposits, and multiple flecks on retinal imaging because some patients showed overlapping phenotypes and clinical diagnosis may obscure the characteristics (Figure 1).

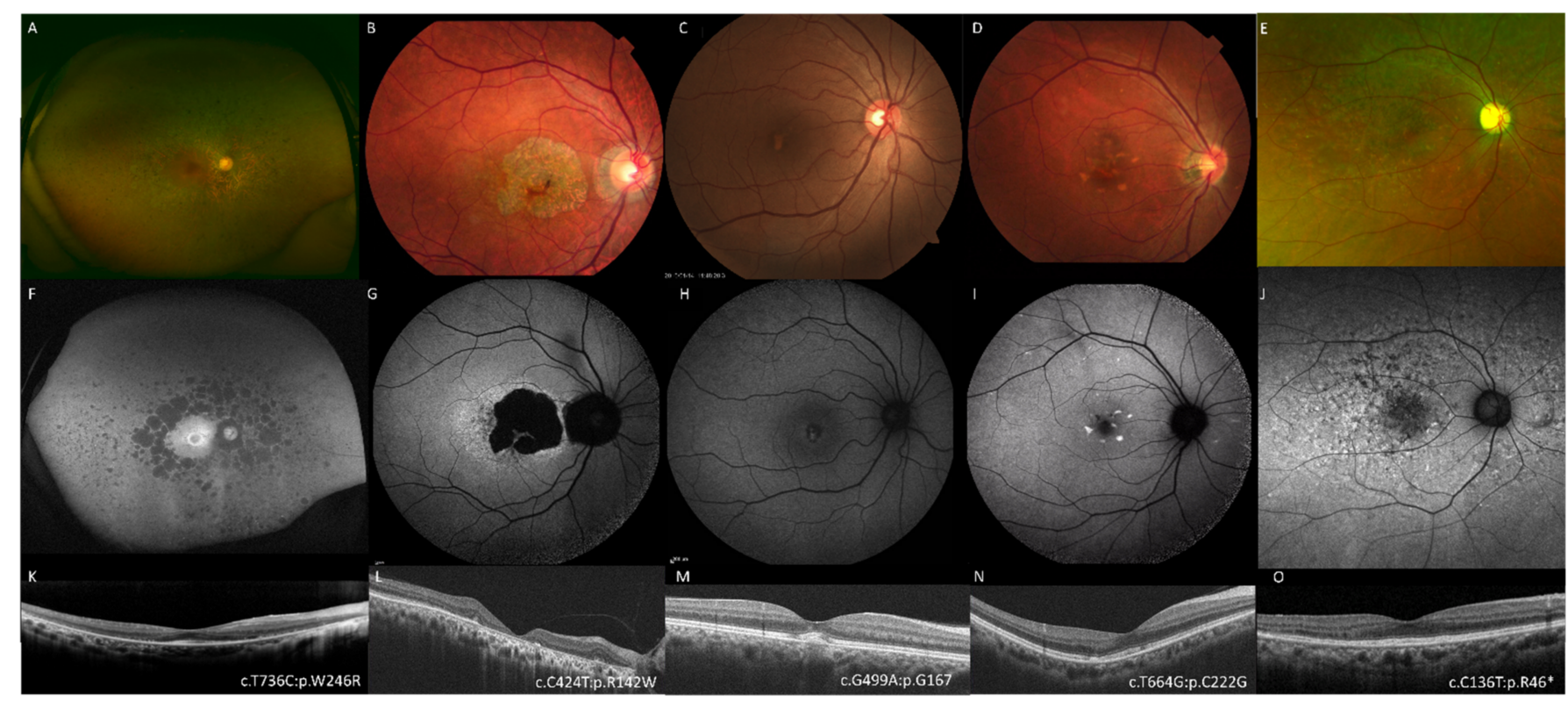

Figure 1. Phenotypic spectrum of patients with $P R P H 2$-associated retinal dystrophy. Images of the fundus (A-E), fundus autofluorescence $(\mathbf{F}-\mathbf{J})$, and optical coherence tomography $(\mathbf{K}-\mathbf{O})$. Some cases showed peripheral atrophy compatible with retinitis pigmentosa (left column, patient KYT6553), macular atrophy compatible with cone/cone-rod dystrophy (the second column, patient NISO 1014-001), Best disease-like foveal deposit (the third column, patient JKI167-1314), pattern dystrophy-like flecks (fourth column, patient NISO112-112), and Stargardt disease-like multiple flecks (the right column, patient UOEH188-1). Causative variants and protein changes are shown.

We obtained family history and assumed the mode of inheritance as autosomal dominant if two generations or more were affected; autosomal recessive if there was parental consanguinity or siblings from normal parents were affected; X-linked if the diseased occurred in multiple generations but without male-to-male transmission and only males were affected.

\subsection{Genetic Screening}

While this study focused on $P R P H 2$, the screening was conducted as a part of comprehensive genetic screening of patients with IRD. Genomic DNA was extracted from peripheral blood samples and analyzed using next-generation sequencer as previously reported. [22,30-33]. Briefly, we employed targeted exome sequencing for case series of 2014 [22], whole genome sequencing for Kyoto University cases after 2014 [32], and whole exome sequencing for the other participants. Subsequently, target analysis of retinal disease-associated genes was performed. We analyzed all the variants in exons and their boundaries ( $\pm 2 \mathrm{bp}$ ) that were detected on the genes registered in Retinal Information Network (RetNet; Available online: https://sph.uth.edu/retnet/ (accessed on 1 September 2021)). The identified variants were filtered based on the allele frequency in the Human Genetic Variation database (HGVD, a database of allele frequency in the general Japanese cohort; Available online: http:/ / www.hgvd.genome.med. kyoto-u.ac.jp/ (accessed on 1 September 2021), Genome Aggregation Database (gnomAD; Available online: https://gnomad.broadinstitute.org/), and 1000 Genomes (Available 
online: http://www.internationalgenome.org/ (accessed on 1 September 2021)). Missense variants were evaluated using seven in silico prediction programs: MutationTaster (http:/ / www.mutationtaster.org/; accessed on 1 September 2021), FATHMM (http:// fathmm.biocompute.org.uk/9; accessed on 1 September 2021), Combined Annotation Dependent Depletion (https:/ / cadd.gs.washington.edu/; accessed on 1 September 2021), SIFT (https://www.sift.co.uk/; accessed on 1 September 2021), PROVEAN (http://provean. jcvi.org/index.php; accessed on 1 September 2021), and Polyphen 2 (http:/ / genetics.bwh. harvard.edu/pph2/; accessed on 1 September 2021). Splice site alteration was assessed using Human Splicing Finder (http: / / umd.be/Redirect.html; accessed on 1 September 2021). The evolutionary conservation score for each variant was calculated using PhyloP30way (https://ccg.epfl.ch/mga/mm9/phylop/phylop.html; accessed on 1 September 2021), and PhastCons30way (https:/ / bioconductor.org/packages/release/data/annotation/html/ phastCons30way.UCSC.hg38.html; accessed on 1 September 2021). Variant classification was performed according to the American College of Medical Genetics and Genomics (ACMG) guidelines [34]. Candidate variants were confirmed by Sanger sequencing in the index patient and their family members, if possible.

\subsection{Statistical Analysis}

Decimal visual acuity was converted to logarithm of the minimum angle of resolution (logMAR) for statistical analysis. Counting finger and hand motion were regarded as logMAR 2.0 and 2.3, respectively [35]. Comparisons between the two groups were performed using the Mann-Whitney U test or chi-square test, as appropriate. Associations between the clinical factors were assessed using the Spearman's rank correlation test. All statistical analyses were performed using IBM SPSS Statistics 26 (IBM Japan, Tokyo, Japan).

\section{Results}

A total of 40 patients from 30 families with 17 distinct $P R P H 2$ variants were identified. Details of the patients are summarized in Table 1 . Some cases have been reported previously $[36,37]$. Twenty patients were men and 20 were women. Based on comprehensive examinations, patients were phenotypically classified into the RP $(n=16), \mathrm{CRD}(n=7)$, and MD $(n=17)$ subgroups. Among patients with MD, four had Best disease-like deposits, and seven had Stargardt disease or pattern dystrophy-like multiple flecks. Three of the four patients with Best disease-like deposits had subnormal EOG. Seven of 16 patients with RP had macular atrophy in addition to typical peripheral atrophy. Meanwhile, two patients with CRD and one patient with MD had peripheral atrophy. Common primary complaints were reduced visual acuity or central visual field loss (16 patients, $40 \%$ ), night blindness (12 patients, 30\%), photophobia (4 patients, 10\%), and peripheral visual field loss (1 patient, $2.5 \%)$. Three $(7.5 \%)$ patients had no symptoms at the time of diagnosis.

Most patients (from 16 families) had autosomal dominant inheritance of PRPH2associated retinal dystrophy, whereas 11 patients had sporadic disease. We could not determine the inheritance pattern in one patient. The pedigree charts of two patients were not available. Some discrepancies in the phenotype subgroups within families were noted. Illustrative cases are presented in Figure 2. An 88-year-old woman had patterndystrophy-like MD and her 61-year-old daughter had RP. The mother showed a lower limit of normal range but still recordable rod and cone responses in ERG, the daughter showed a non-recordable rod and barely recordable cone responses. 
Table 1. Clinical characteristics of patients with $P R P H 2$-associated retinal dystrophy.

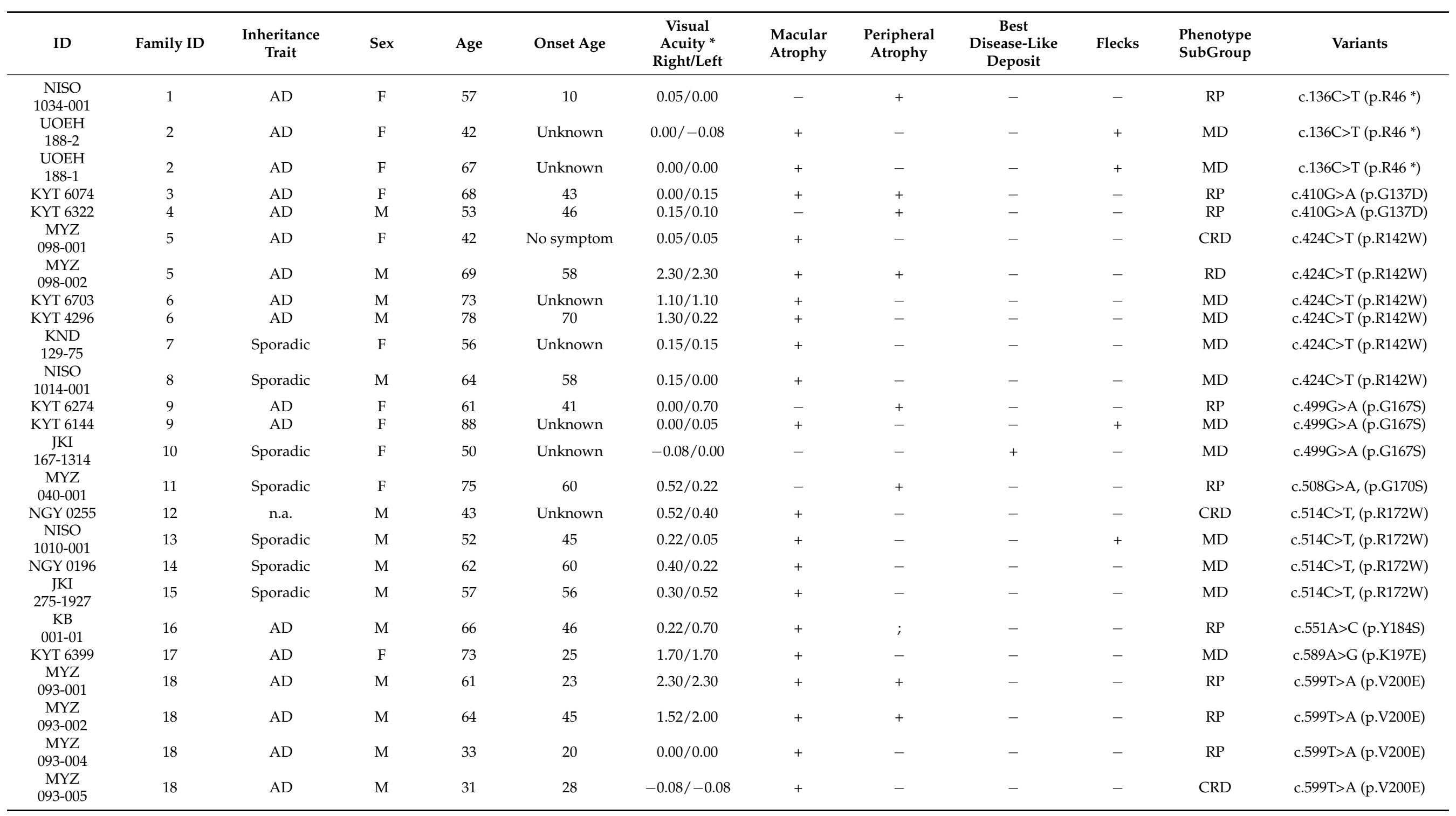


Table 1. Cont.

\begin{tabular}{|c|c|c|c|c|c|c|c|c|c|c|c|c|}
\hline ID & Family ID & $\begin{array}{l}\text { Inheritance } \\
\text { Trait }\end{array}$ & Sex & Age & Onset Age & $\begin{array}{c}\text { Visual } \\
\text { Acuity * } \\
\text { Right/Left }\end{array}$ & $\begin{array}{l}\text { Macular } \\
\text { Atrophy }\end{array}$ & $\begin{array}{l}\text { Peripheral } \\
\text { Atrophy }\end{array}$ & $\begin{array}{c}\text { Best } \\
\text { Disease-Like } \\
\text { Deposit }\end{array}$ & Flecks & $\begin{array}{l}\text { Phenotype } \\
\text { SubGroup }\end{array}$ & Variants \\
\hline $\begin{array}{c}\text { MYZ } \\
101-001\end{array}$ & 19 & $\mathrm{AD}$ & $\mathrm{F}$ & 32 & 29 & $0.30 / 0.30$ & + & - & - & - & CRD & c.599T >A (p.V200E) \\
\hline $\begin{array}{c}\text { MYZ } \\
101-003\end{array}$ & 19 & $\mathrm{AD}$ & $\mathrm{F}$ & 52 & 5 & $1.30 / 1.22$ & + & - & - & - & CRD & c.599T >A (p.V200E) \\
\hline $\begin{array}{c}\text { MYZ } \\
066-001\end{array}$ & 20 & $\mathrm{AD}$ & $\mathrm{F}$ & 40 & 32 & $0.40 / 0.52$ & + & + & - & - & CRD & c.599T>A (p.V200E) \\
\hline NGY 0148 & 21 & $\mathrm{AD}$ & M & 49 & Unknown & $0.00 / 0.00$ & + & - & - & + & MD & c.641G>A (p.C214Y) \\
\hline $\begin{array}{c}\text { NISO } \\
112-112\end{array}$ & 22 & Sporadic & M & 49 & 14 & $-0.08 / 0.00$ & + & + & - & - & MD & c. $664 \mathrm{~T}>\mathrm{G}(\mathrm{p} . \mathrm{C} 222 \mathrm{G})$ \\
\hline $\begin{array}{l}\text { KND } \\
109-38\end{array}$ & 23 & $\mathrm{AD}$ & $\mathrm{F}$ & 28 & 8 & $0.00 / 0.00$ & - & + & - & - & $\mathrm{RP}$ & $\begin{array}{c}\text { c.670_681del } \\
\text { (p.Q224_I227del) }\end{array}$ \\
\hline $\begin{array}{l}\text { KND } \\
109-51\end{array}$ & 23 & $\mathrm{AD}$ & M & 30 & 14 & $-0.08 /-0.08$ & - & + & - & - & $\mathrm{RP}$ & $\begin{array}{c}\text { c.670_681del } \\
\text { (p.Q224_I227del) }\end{array}$ \\
\hline $\begin{array}{l}\text { KND } \\
109-52\end{array}$ & 23 & $\mathrm{AD}$ & M & 67 & 27 & $2.00 / 1.52$ & + & + & - & - & $\mathrm{RP}$ & $\begin{array}{c}\text { c.670_681del } \\
\text { (p.Q224_I227del) }\end{array}$ \\
\hline KYT 6553 & 24 & $\mathrm{AD}$ & $\mathrm{F}$ & 58 & 15 & $0.05 / 0.05$ & - & + & - & - & $\mathrm{RP}$ & c.736T $>$ C (p.W246R) \\
\hline $\begin{array}{c}\text { JKI } \\
060-0665\end{array}$ & 25 & $\mathrm{AD}$ & M & 48 & 45 & $-0.08 /-0.18$ & - & - & + & - & $\mathrm{RP}$ & c. $748 \mathrm{~T}>\mathrm{G}$ (p.C250G) \\
\hline KYT 6237 & 26 & n.a. & $\mathrm{F}$ & 49 & Unknown & $-0.18 / 0.05$ & - & - & + & - & MD & c.748T>G (p.C250G) \\
\hline $\begin{array}{c}\text { JKI } \\
077-0735\end{array}$ & 28 & Sporadic & M & 58 & 56 & $-0.08 / 0.00$ & + & - & + & + & $\mathrm{MD}$ & $\begin{array}{c}\text { c.809_810del } \\
\text { (p.L270Pfs *30) }\end{array}$ \\
\hline $\begin{array}{c}\text { NISO } \\
4002-001\end{array}$ & 29 & Sporadic & F & 38 & 6 & $1.70 / 1.52$ & - & + & - & - & $\mathrm{RP}$ & c.828G $>$ T (p.E276D) \\
\hline $\begin{array}{c}\text { NISO } \\
3001-001\end{array}$ & 30 & $\mathrm{AD} / \mathrm{AR}$ & $\mathrm{F}$ & 59 & 50 & $0.52 / 0.52$ & + & + & - & - & $\mathrm{RP}$ & $\begin{array}{c}\text { c.828_828+5 } \\
\text { delGGTAGGinsC }\end{array}$ \\
\hline
\end{tabular}

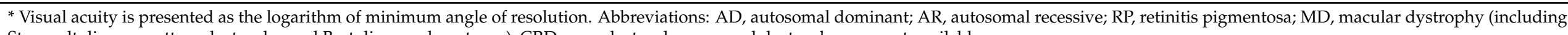
Stargardt disease, pattern dystrophy, and Best disease phenotypes); CRD, cone dystrophy, cone-rod dystrophy; n.a., not available. 

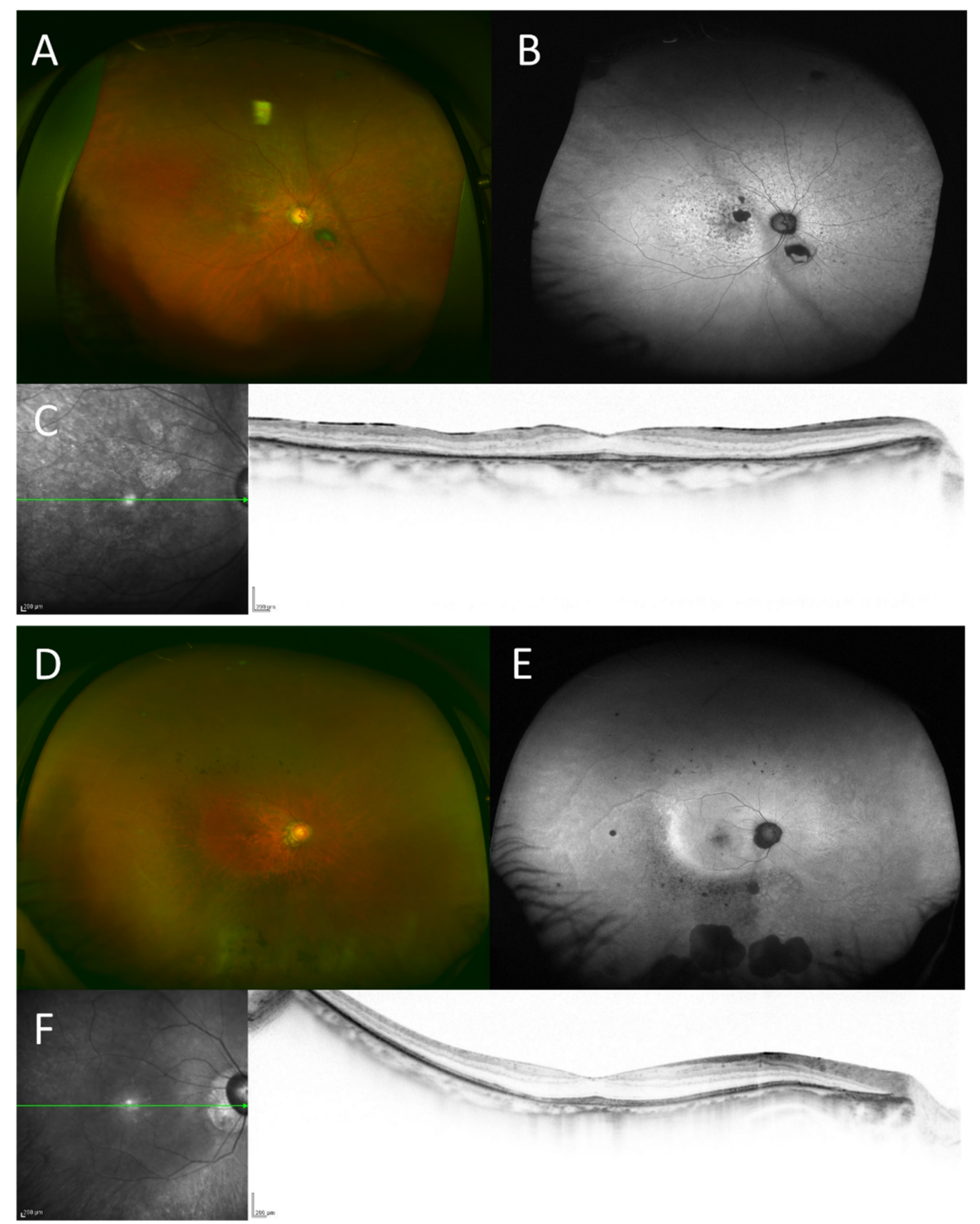

Figure 2. Illustrative cases (patient KYT6144, A-C and KYT6274, D-F) with different phenotypes in a family sharing the same $P R P H 2$ variant (c.499G>A). Images of the fundus (A) and fundus autofluorescence $(\mathbf{B})$ in the 88-year-old mother revealing macular atrophy. Thinning of outer retinal layer and disruption of ellipsoid zone are observed in the parafoveal area. (C) Electroretinogram of the patient showing normal rod and cone response. Meanwhile, midperipheral atrophy, predominantly in the inferior retina, is observed in her 61-year-old daughter $(\mathbf{D}, \mathbf{E})$. The macula is relatively spared; however, thinning of the outer retinal layer toward the periphery is observed. $(F)$ Electroretinogram of the patient showing non-recordable rod and barely recordable cone responses.

Two patients developed choroidal neovascularization (CNV). Both patients were classified into the RP phenotype subgroup. The images of the fundus and OCT are presented in Figure 3. One of the patients had high myopia with a spherical equivalent of -10.5 diopter. Anti-vascular endothelial growth factor therapy was not available at that time. Visual acuity declined from $0.7(20 / 30)$ to $0.1(20 / 200)$ in 15 years with the progression of macular atrophy. Another patient presented with bilateral CNV without 
evident drusen. She had received $>60$ intravitreal injections of anti-vascular endothelial growth factor agents for the left eye in 13 years and part of the treatment course was reported elsewhere [37]. She developed CNV in the right eye 8 years after the start of treatment in the left eye. Visual acuity declined from $0.7(20 / 30)$ to $0.2(20 / 100)$ in the left and from $1.0(20 / 20)$ to $0.4(20 / 50)$ in 13 and 5 years, respectively.
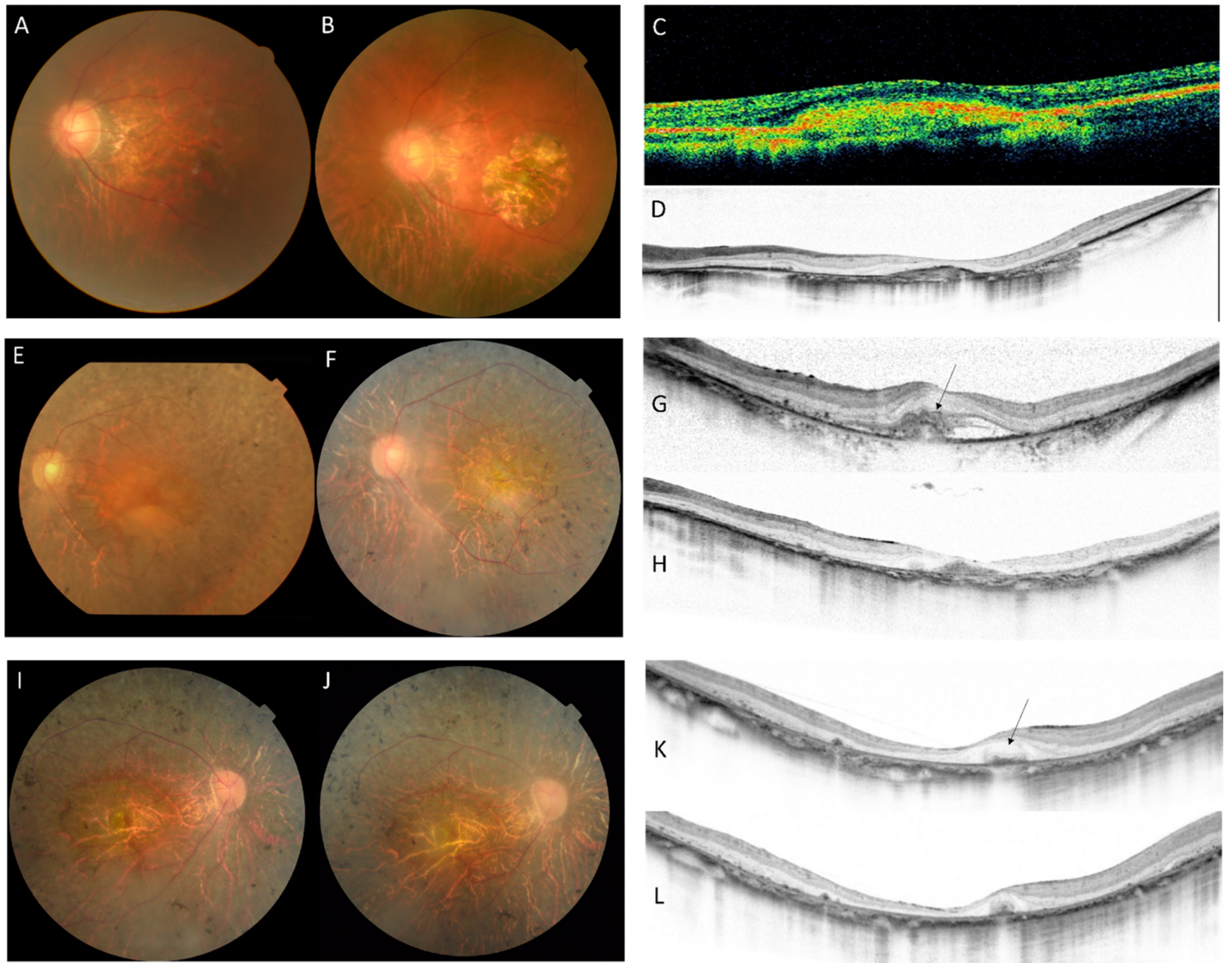

Figure 3. Illustrative cases with pathogenic variants in PRPH2 (patient KYT6274 and KYT6074) who developed choroidal neovascularization $(\mathrm{CNV})$ in association with retinitis pigmentosa. Patient KYT6274 had high myopia and developed $\mathrm{CNV}$ at the age of 49 years. (A) Macular atrophy progressed in 13 years. (B) CNV at 2 years after development (C) CNV at 13 years after development (D) Unfortunately, OCT images of new-onset CNV were not available. Patient KYT6074 developed the CNV in the left and right eyes at the age of 55 and 65 years, respectively. (E,G,I,K) The patient received multiple injections of anti-vascular endothelial growth factor agents. Fibrotic atrophy and macular thinning were observed at the final visit $(\mathbf{F}, \mathbf{H}, \mathbf{J}, \mathbf{L})$. CNVs are indicated with arrows on OCT images.

The age of the patients ranged from 28 to 88 years. The age of onset was generally in the $40^{\prime}$ s; however, some patients had the onset as early as 5 years of age. No association was found between the age of onset and sex or visual acuity; however, patients with RP tended to develop symptoms earlier than patients with CRD or MD (31.2 vs. 40.9 years, $p=0.161)$.

Visual acuity of the patients ranged from hand motion $(\log M A R$ equivalent 2.3$)$ to 1.5 (Snellen equivalent 20/13, logMAR equivalent -0.18). No significant difference in BCVA was noted among patients with RP, those with CRD, and those with MD. As expected from 
the irreversible and progressive nature of the disease, BCVA tended to be worse in elderly patients (Spearman's correlation $=0.36, p=0.22$ ).

The data of the detected variants are presented in Tables 2 and 3. Eleven variants were previously reported, whereas six were novel. Twelve variants were missense, two were splice site, one was a frameshift, one was a stop gain, and one was an in-frame deletion. The locations of the variants in the amino acid sequence are illustrated in Figure 4. All missense variants were located in the D2 loop of the protein. None of the cases had likely pathogenic or pathogenic variants in ROM1.

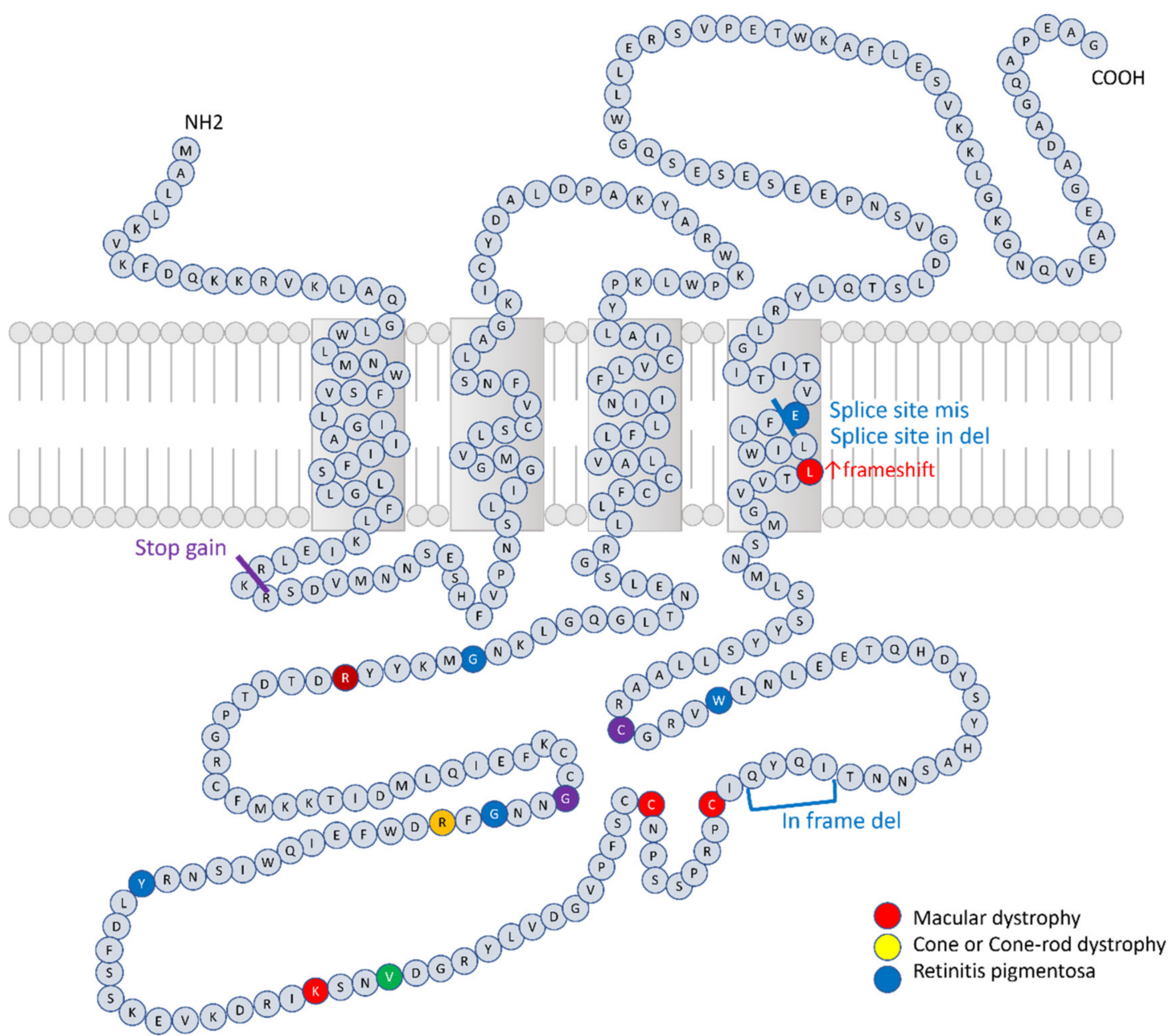

Figure 4. Schematic model of amino acid sequence of peripherin and variants found in the present study. (The presentation style has been adapted from Boon et al. Prog Ret Eye Res 2008 [3]. Sequence is based on NP_000313.2). Missense or in-frame deletions are shown as colored residues and premature termination and frameshift variants are shown as colored bars. When a locus is associated with various phenotype, they were indicated by mixed colors e.g., red + yellow $=$ orange, yellow + blue $=$ green, red + blue $=$ purple, and red + yellow + blue $=$ brown . 
Table 2. Allele frequency of the $P R P H 2$ variants identified in the present study.

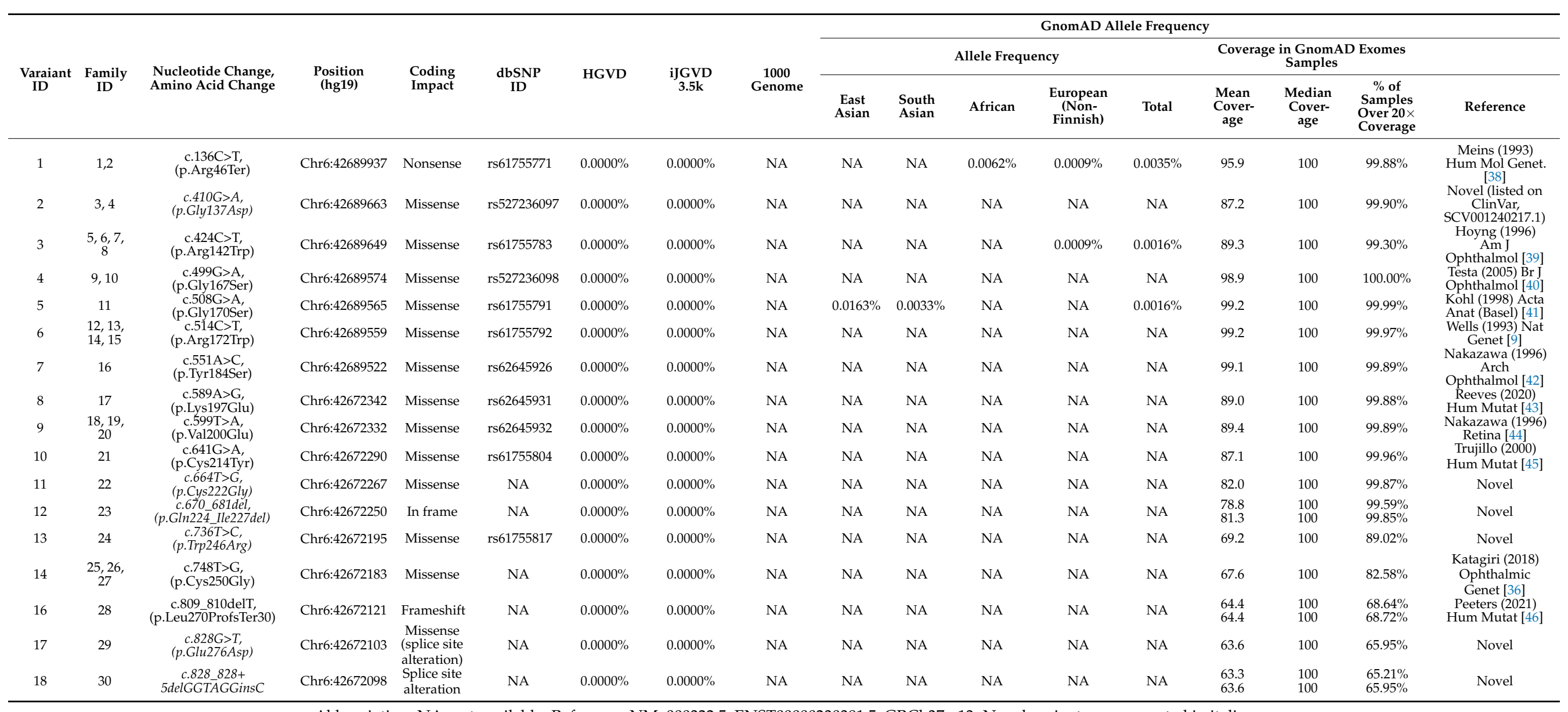

Abbreviation: NA, not available. Reference: NM_000322.5, ENST00000230381.5, GRCh37.p13. Novel variants are presented in italic. 
Table 3. Results of in-silico prediction and ACMG classification.

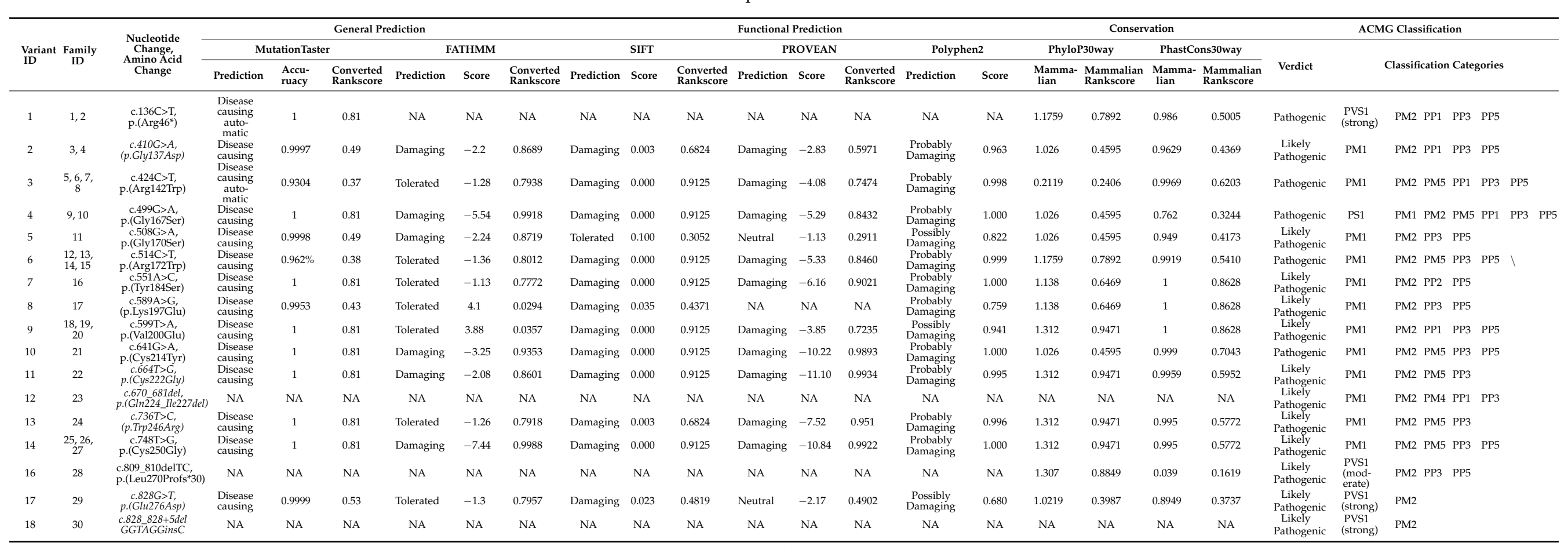

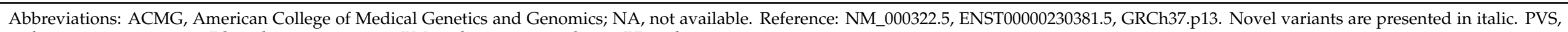
pathogenicity very strong; PS, pathogenicity strong; PM, pathogenicity moderate; PP, pathogenicity supporting.
pation 


\section{Discussion}

Here, we present the clinical and genetic features of 40 patients with PRPH2-associated retinal dystrophy. To the best of our knowledge, this is the largest cohort among Asian ethnicities. This study confirmed phenotypic variability, even within the same family. The present data provide novel insights into genotype-phenotype associations in East Asian ethnicity.

Previous reports have suggested association between the location of the variant in PRPH2 and clinical phenotype. Specifically, variants are mostly found in the D2 loop $[13,43,46-48]$, which is critical for protein-protein interactions. Variants that cause autosomal dominant RP tend to accumulate between Lys193 and Glu226 [3]. Particularly, missense mutations in Pro210 to Pro216 cause autosomal dominant RP [3]. Patients diagnosed with CRD, RP, and STGD tend to have variants in exon 1, whereas patients with Best disease and pattern dystrophy tend to have variants in exon $2[13,43]$. Patients with p.Arg172Trp present earlier onset than those with other alleles [43]. Some of these findings are compatible with the findings of the present cohort; 14 of $17(82.3 \%)$ identified variants were in the D2 loop. Six of 16 patients (from two of ten families) with RP had variants between Lys193 and Glu226. The Best disease- or pattern dystrophy-like deposits were found in 10 patients. Five of these 10 patients had variants in exon 2 . However, the age of onset in four patients with p.Arg172Trp was 45-60 years. The results reveal the difficulty in establishing a clear genotype-phenotype correlation.

The prevalence of founder variants was found to be different. In Caucasians, c.424C $>\mathrm{T}$ (p.Arg142Trp) and c.514C >T (p.Arg172Trp) are common causative variants. Other recurrent variants are c.136C $>\mathrm{T}$ (p.Arg46*), c.422A>G (p.Tyr141Cys), c.441del (p.Gly148Alafs*5), c.514C >G (p.Arg172Gln), c.554T>C (p.Leu185Pro), c.584G >T (p.Arg195Leu), c.623G >A (p.Gly208Asp), c.629C >G (p.Pro210Arg), c.646C >T (p.Pro216Ser), c.647C >T (p.Pro216Leu), c.715C > T (p.Gln239*), c.866C > T (p.Ser289Leu), and c.828+3A > T [13,43,46,49]. Among these variants, c.514C $>\mathrm{T}$ was reported in a previous study in Japan [50] and was found in four patients from four families in our cohort. The variant c. $424 \mathrm{C}>\mathrm{T}$ was found in four families and c.136C $>\mathrm{T}$ was found in two families. However, other variants were not found in the present study or in previous studies in Japan [42,44,50-58]. Instead, c.599T>A (p.V200E) reported in a previous study in Japan [51] was found in seven patients from three families in the present study. Of note, the locations of the institutions where the previous study was conducted and where the patients were recruited in the present study were $1600 \mathrm{~km}$ apart. The results indicate ethnicity-based characteristic variants in the Japanese population, as well as shared variants among multiple ethnicities. The inter-ethnic differences should be considered when interpreting $P R P H 2$ variants in patients with IRD.

CNV was relatively common $(2 / 40,5 \%)$ in our cohort. CNV occasionally occurs in IRD, but is not a common complication, especially in RP [59]. One of the patients was considered to have myopic CNV. The other patient might have been complicated with neovascular age-related macular degeneration (AMD), but drusen, a hallmark of AMD, was not evident. We assumed that the patient developed dystrophy-associated CNV. The development of $\mathrm{CNV}$ is generally discussed in association with pattern dystrophy [3,60]; however, it can be seen in the RP phenotype as previously reported [61]. Considering that anti-vascular endothelial growth factor therapy is an effective treatment for CNV. Patients should be advised to visit the eye clinic when they notice acute vision loss and/or metamorphopsia.

This study has some limitations. First, the prevalence of $P R P H 2$-associated dystrophy could not be determined. Each institution recruited patients independently and the criteria to proceed to genetic testing may have been different in each institution. Patients with a dominant inheritance pattern may be more willing to undergo genetic testing. Nevertheless, 40 cases were sufficient to determine the phenotypic variability within the cohort. Second, the pathogenicity of each variant is based on the standard criteria but not on solid biological evidence. Although we systematically applied ACMG guidelines and graded all identified variants as pathogenic or likely pathogenic, there is still a chance that some of these variants are bystanders and pathogenic variants are present in other loci or genes. Finally, we did 
not intensively investigate the disease modifying effect of ROM1 variants. While none of the patients had likely pathogenic or pathogenic variants in ROM1, variants filtered out or beyond the target lesion may modify the phenotype.

\section{Conclusions}

We analyzed 40 Japanese patients with PRPH2-associated retinal dystrophy and confirmed the genotypic and phenotypic variations of the disease in the Japanese population. Further studies involving multiple ethnicities would enhance our understanding of the disease.

Author Contributions: Conceptualization, A.O., K.F. and K.T.; methodology, A.O., K.F. and K.T.; formal analysis, K.F.; investigation and resources, all authors; data curation, K.F.; writing-original draft preparation, A.O. and K.F.; writing—review and editing, G.M., N.N., Y.I., S.U., K.K., T.H., H.K., A.M., K.S., S.K., M.N., T.I., A.T. and K.T.; supervision, T.I. and A.T.; funding acquisition, A.O., K.F. and T.I. All authors have read and agreed to the published version of the manuscript.

Funding: Akio Oishi is supported by grants from the Japan Society for the Promotion of Science, Tokyo, Japan (17H06820 and 19K09929) and the Takeda Science Foundation. Kaoru Fujinami is supported by grants from the Japan Society for the Promotion of Science (16H06269); grants from Grant-in-Aid for Scientists to support international collaborative studies of the Ministry of Education, Culture, Sports, Science and Technology, Japan (16KK01930002); grants from the National Hospital Organization Network Research Fund (H30-NHO-Sensory Organs-03), grants from FOUNDATION FIGHTING BLINDNESS ALAN LATIES CAREER DEVELOPMENT PROGRAM (CF-CL-0416-0696UCL), grants from Health Labor Sciences Research Grant, The Ministry of Health Labor and Welfare (201711107A), and Charitable Trust Fund for Ophthalmic Research in Commemoration of Santen Pharmaceutical's Founder. Takeshi Iwata is supported by the Japan Agency for Medical Research and Development (AMED) (18ek0109282h0002).

Institutional Review Board Statement: The study was conducted in accordance with the guidelines of the Declaration of Helsinki and was approved by the Institutional Ethics Committees of the National Institute of Sensory Organs, National Hospital Organization Tokyo Medical Center, (Reference: R18-029) and Kyoto University Graduate School of Medicine (Reference: G0746).

Informed Consent Statement: Informed consent was obtained from all subjects involved in the study.

Data Availability Statement: Data are available upon reasonable request.

Acknowledgments: We specially thank Lizhu Yang, Yu Fujinami-Yokokawa, and Xiao Liu, Keio University School of Medicine, Tokyo, Japan, and Kazutoshi Yoshitake, National Institute of Sensory Organs, National Hospital Organization Tokyo Medical Center, for their helpful support in genetic analyses. We also thank all Japan Eye Genetics Consortium members. Mineo Kondo, Shuhei Kameya, Taro Kominami, Hiroko Terasaki, Hiroyuki Sakuramoto, Satoshi Katagiri, Kei Mizobuchi, Natsuko Nakamura, Toshihide Kurihara, Kazuo Tsubota, Yozo Miyake, Kazutoshi Yoshitake, Toshihide Nishimura, Yoshihide Hayashizaki, Nobuhiro Shimozawa, Masayuki Horiguchi, Shuichi Yamamoto, Manami Kuze, Shigeki Machida, Yoshiaki Shimada, Takashi Fujikado, Yoshihiro Hotta, Masayo Takahashi, Kiyofumi Mochizuki, Akira Murakami, Susumu Ishida, Mitsuru Nakazawa, Tetsuhisa Hatase, Tatsuo Matsunaga, Akiko Maeda, Kosuke Noda, Atsuhiro Tanikawa, Syuji Yamamoto, Hiroyuki Yamamoto, Makoto Araie, Makoto Aihara, Toru Nakazawa, Tetsuju Sekiryu, Kenji Kashiwagi, Kenjiro Kosaki, Carninci Piero, Takeo Fukuchi, Atsushi Hayashi, Katsuhiro Hosono, Keisuke Mori, Kouji Tanaka, Koichi Furuya, Keiichirou Suzuki, Ryo Kohata, Yasuo Yanagi, Yuriko Minegishi, Daisuke Iejima, Akiko Suga, Brian P Rossmiller, Yang Pan, Tomoko Oshima, Mao Nakayama, Megumi Yamamoto, Naoko Minematsu, Daisuke Mori, Yusuke Kijima, Kentaro Kurata, Norihiro Yamada, Masayoshi Itoh, Hideya Kawaji, Yasuhiro Murakawa, Ryo Ando, Wataru Saito, Yusuke Murakami, Hiroaki Miyata, Lizhu Yang, Yu Fujinami-Yokokawa, Xiao Liu, Gavin Arno, Nikolas Pontikos, Mihori Kita, Hiroshi Hirose, Katsuyuki Sakai, Yasumasa Otori, Yasuhiro Yamada, Kazuki Yamazawa, Satomi Inoue, and Takayuki Kinoshita.

Conflicts of Interest: The authors declare no conflict of interest. 


\section{References}

1. Broadgate, S.; Yu, J.; Downes, S.M.; Halford, S. Unravelling the genetics of inherited retinal dystrophies: Past, present and future. Prog. Retin. Eye Res. 2017, 59, 53-96. [CrossRef]

2. Ku, C.A.; Pennesi, M.E. The new landscape of retinal gene therapy. Am. J. Med Genet. Part C Semin. Med Genet. 2020, 184, 846-859. [CrossRef]

3. Boon, C.J.; den Hollander, A.I.; Hoyng, C.B.; Cremers, F.P.; Klevering, B.J.; Keunen, J.E. The spectrum of retinal dystrophies caused by mutations in the peripherin/RDS gene. Prog. Retin. Eye Res. 2008, 27, 213-235. [CrossRef]

4. Stuck, M.W.; Conley, S.M.; Naash, M.I. PRPH2/RDS and ROM-1: Historical context, current views and future considerations. Prog. Retin. Eye Res. 2016, 52, 47-63. [CrossRef] [PubMed]

5. Khan, A.O.; Al Rashaed, S.; Neuhaus, C.; Bergmann, C.; Bolz, H.J. Peripherin mutations cause a distinct form of recessive Leber congenital amaurosis and dominant phenotypes in asymptomatic parents heterozygous for the mutation. Br. J. Ophthalmol. 2016, 100, 209-215. [CrossRef] [PubMed]

6. Dryja, T.P.; Hahn, L.B.; Kajiwara, K.; Berson, E.L. Dominant and digenic mutations in the peripherin/RDS and ROM1 genes in retinitis pigmentosa. Invest. Ophthalmol. Vis. Sci. 1997, 38, 1972-1982. [PubMed]

7. Kajiwara, K.; Berson, E.L.; Dryja, T.P. Digenic retinitis pigmentosa due to mutations at the unlinked peripherin/RDS and ROM1 loci. Science 1994, 264, 1604-1608. [CrossRef]

8. Donato, L.; Abdalla, E.M.; Scimone, C.; Alibrandi, S.; Rinaldi, C.; Nabil, K.M.; D'Angelo, R.; Sidoti, A. Impairments of Photoreceptor Outer Segments Renewal and Phototransduction Due to a Peripherin Rare Haplotype Variant: Insights from Molecular Modeling. Int. J. Mol. Sci. 2021, 22, 3484. [CrossRef]

9. Wells, J.; Wroblewski, J.; Keen, J.; Inglehearn, C.; Jubb, C.; Eckstein, A.; Jay, M.; Arden, G.; Bhattacharya, S.; Fitzke, F.; et al. Mutations in the human retinal degeneration slow (RDS) gene can cause either retinitis pigmentosa or macular dystrophy. Nat. Genet. 1993, 3, 213-218. [CrossRef]

10. Roosing, S.; Thiadens, A.A.; Hoyng, C.B.; Klaver, C.C.; den Hollander, A.I.; Cremers, F.P. Causes and consequences of inherited cone disorders. Prog. Retin. Eye Res. 2014, 42, 1-26. [CrossRef]

11. Leroy, B.P.; Kailasanathan, A.; De Laey, J.J.; Black, G.C.; Manson, F.D. Intrafamilial phenotypic variability in families with RDS mutations: Exclusion of ROM1 as a genetic modifier for those with retinitis pigmentosa. Br. J. Ophthalmol. 2007, 91, 89-93. [CrossRef]

12. Daftarian, N.; Mirrahimi, M.; Sabbaghi, H.; Moghadasi, A.; Zal, N.; Dehghan Banadaki, H.; Ahmadieh, H.; Suri, F. PRPH2 mutation as the cause of various clinical manifestations in a family affected with inherited retinal dystrophy. Ophthalmic. Genet. 2019, 40, 436-442. [CrossRef] [PubMed]

13. Pontikos, N.; Arno, G.; Jurkute, N.; Schiff, E.; Ba-Abbad, R.; Malka, S.; Gimenez, A.; Georgiou, M.; Wright, G.; Armengol, M.; et al. Genetic Basis of Inherited Retinal Disease in a Molecularly Characterized Cohort of More Than 3000 Families from the United Kingdom. Ophthalmology 2020, 127, 1384-1394. [CrossRef]

14. Conley, S.M.; Stuck, M.W.; Watson, J.N.; Naash, M.I. Rom1 converts Y141C-Prph2-associated pattern dystrophy to retinitis pigmentosa. Hum. Mol. Genet. 2017, 26, 509-518. [CrossRef]

15. Poloschek, C.M.; Bach, M.; Lagreze, W.A.; Glaus, E.; Lemke, J.R.; Berger, W.; Neidhardt, J. ABCA4 and ROM1: Implications for modification of the PRPH2-associated macular dystrophy phenotype. Invest. Ophthalmol. Vis. Sci. 2010, 51, 4253-4265. [CrossRef]

16. Martin-Merida, I.; Aguilera-Garcia, D.; Fernandez-San Jose, P.; Blanco-Kelly, F.; Zurita, O.; Almoguera, B.; Garcia-Sandoval, B.; Avila-Fernandez, A.; Arteche, A.; Minguez, P.; et al. Toward the Mutational Landscape of Autosomal Dominant Retinitis Pigmentosa: A Comprehensive Analysis of 258 Spanish Families. Invest. Ophthalmol. Vis. Sci. 2018, 59, 2345-2354. [CrossRef] [PubMed]

17. Birtel, J.; Eisenberger, T.; Gliem, M.; Muller, P.L.; Herrmann, P.; Betz, C.; Zahnleiter, D.; Neuhaus, C.; Lenzner, S.; Holz, F.G.; et al. Clinical and genetic characteristics of 251 consecutive patients with macular and cone/cone-rod dystrophy. Sci. Rep. 2018, 8, 4824 . [CrossRef] [PubMed]

18. Gill, J.S.; Georgiou, M.; Kalitzeos, A.; Moore, A.T.; Michaelides, M. Progressive cone and cone-rod dystrophies: Clinical features, molecular genetics and prospects for therapy. Br. J. Ophthalmol. 2019, 103, 711-720. [CrossRef]

19. Manes, G.; Guillaumie, T.; Vos, W.L.; Devos, A.; Audo, I.; Zeitz, C.; Marquette, V.; Zanlonghi, X.; Defoort-Dhellemmes, S.; Puech, B.; et al. High prevalence of PRPH2 in autosomal dominant retinitis pigmentosa in france and characterization of biochemical and clinical features. Am. J. Ophthalmol. 2015, 159, 302-314. [CrossRef]

20. Gao, F.J.; Li, J.K.; Chen, H.; Hu, F.Y.; Zhang, S.H.; Qi, Y.H.; Xu, P.; Wang, D.D.; Wang, L.S.; Chang, Q.; et al. Genetic and Clinical Findings in a Large Cohort of Chinese Patients with Suspected Retinitis Pigmentosa. Ophthalmology 2019, 126, 1549-1556. [CrossRef]

21. Yoon, C.K.; Kim, N.K.; Joung, J.G.; Shin, J.Y.; Park, J.H.; Eum, H.H.; Lee, H.O.; Park, W.Y.; Yu, H.G. The diagnostic application of targeted re-sequencing in Korean patients with retinitis pigmentosa. BMC Genom. 2015, 16, 515. [CrossRef]

22. Oishi, M.; Oishi, A.; Gotoh, N.; Ogino, K.; Higasa, K.; Iida, K.; Makiyama, Y.; Morooka, S.; Matsuda, F.; Yoshimura, N. Comprehensive molecular diagnosis of a large cohort of Japanese retinitis pigmentosa and usher syndrome patients by nextgeneration sequencing. Invest. Ophthalmol. Vis. Sci. 2014, 55, 7369-7375. [CrossRef] 
23. Koyanagi, Y.; Akiyama, M.; Nishiguchi, K.M.; Momozawa, Y.; Kamatani, Y.; Takata, S.; Inai, C.; Iwasaki, Y.; Kumano, M.; Murakami, Y.; et al. Genetic characteristics of retinitis pigmentosa in 1204 Japanese patients. J. Med. Genet. 2019, 56, 662-670. [CrossRef] [PubMed]

24. Maeda, A.; Yoshida, A.; Kawai, K.; Arai, Y.; Akiba, R.; Inaba, A.; Takagi, S.; Fujiki, R.; Hirami, Y.; Kurimoto, Y.; et al. Development of a molecular diagnostic test for Retinitis Pigmentosa in the Japanese population. Jpn. J. Ophthalmol. 2018, 62, 451-457. [CrossRef] [PubMed]

25. Oishi, M.; Oishi, A.; Gotoh, N.; Ogino, K.; Higasa, K.; Iida, K.; Makiyama, Y.; Morooka, S.; Matsuda, F.; Yoshimura, N. Nextgeneration sequencing-based comprehensive molecular analysis of 43 Japanese patients with cone and cone-rod dystrophies. Mol. Vis. 2016, 22, 150-160. [PubMed]

26. Tsunoda, K. Investigations of gene pathogenicity and establishment of a patient data bank for the hereditary chorioretinal dystrophy. Nippon Ganka Gakkai Zasshi 2020, 124, 247-284.

27. Marmor, M.F.; Fulton, A.B.; Holder, G.E.; Miyake, Y.; Brigell, M.; Bach, M. ISCEV Standard for full-field clinical electroretinography (2008 update). Doc. Ophthalmol. 2009, 118, 69-77. [CrossRef]

28. McCulloch, D.L.; Marmor, M.F.; Brigell, M.G.; Hamilton, R.; Holder, G.E.; Tzekov, R.; Bach, M. ISCEV Standard for full-field clinical electroretinography (2015 update). Doc. Ophthalmol. 2015, 130, 1-12. [CrossRef]

29. Constable, P.A.; Bach, M.; Frishman, L.J.; Jeffrey, B.G.; Robson, A.G. ISCEV Standard for clinical electro-oculography (2017 update). Doc. Ophthalmol. 2017, 134, 1-9. [CrossRef]

30. Fujinami-Yokokawa, Y.; Fujinami, K.; Kuniyoshi, K.; Hayashi, T.; Ueno, S.; Mizota, A.; Shinoda, K.; Arno, G.; Pontikos, N.; Yang, L.; et al. Clinical and Genetic Characteristics of 18 Patients from 13 Japanese Families with CRX-associated retinal disorder: Identification of Genotype-phenotype Association. Sci. Rep. 2020, 10, 9531. [CrossRef]

31. Fujinami, K.; Kameya, S.; Kikuchi, S.; Ueno, S.; Kondo, M.; Hayashi, T.; Shinoda, K.; Machida, S.; Kuniyoshi, K.; Kawamura, Y.; et al. Novel RP1L1 Variants and Genotype-Photoreceptor Microstructural Phenotype Associations in Cohort of Japanese Patients With Occult Macular Dystrophy. Invest. Ophthalmol. Vis. Sci. 2016, 57, 4837-4846. [CrossRef]

32. Numa, S.; Oishi, A.; Higasa, K.; Oishi, M.; Miyata, M.; Hasegawa, T.; Ikeda, H.O.; Otsuka, Y.; Matsuda, F.; Tsujikawa, A. EYS is a major gene involved in retinitis pigmentosa in Japan: Genetic landscapes revealed by stepwise genetic screening. Sci. Rep. 2020, 10, 20770. [CrossRef] [PubMed]

33. Fujinami, K.; Oishi, A.; Yang, L.; Arno, G.; Pontikos, N.; Yoshitake, K.; Fujinami-Yokokawa, Y.; Liu, X.; Hayashi, T.; Katagiri, S.; et al. Clinical and genetic characteristics of 10 Japanese patients with PROM1-associated retinal disorder: A report of the phenotype spectrum and a literature review in the Japanese population. Am. J. Med Genet. Part. C Semin. Med Genet. 2020, 184, 656-674. [CrossRef]

34. Richards, S.; Aziz, N.; Bale, S.; Bick, D.; Das, S.; Gastier-Foster, J.; Grody, W.W.; Hegde, M.; Lyon, E.; Spector, E.; et al. Standards and guidelines for the interpretation of sequence variants: A joint consensus recommendation of the American College of Medical Genetics and Genomics and the Association for Molecular Pathology. Genet. Med. 2015, 17, 405-424. [CrossRef] [PubMed]

35. Lange, C.; Feltgen, N.; Junker, B.; Schulze-Bonsel, K.; Bach, M. Resolving the clinical acuity categories "hand motion" and "counting fingers" using the Freiburg Visual Acuity Test (FrACT). Graefes Arch. Clin. Exp. Ophthalmol. 2009, 247, 137-142. [CrossRef]

36. Katagiri, S.; Hayashi, T.; Mizobuchi, K.; Yoshitake, K.; Iwata, T.; Nakano, T. Autosomal dominant retinitis pigmentosa with macular involvement associated with a disease haplotype that included a novel PRPH2 variant (p.Cys250Gly). Ophthalmic. Genet. 2018, 39, 357-365. [CrossRef]

37. Miyata, M.; Oishi, A.; Oishi, M.; Hasegawa, T.; Ikeda, H.O.; Tsujikawa, A. Long-term efficacy and safety of anti-VEGF therapy in retinitis pigmentosa: A case report. BMC Ophthalmol. 2018, 18, 248. [CrossRef]

38. Meins, M.; Grüning, G.; Blankenagel, A.; Krastel, H.; Reck, B.; Fuchs, S.; Schwinger, E.; Gal, A. Heterozygous 'Null Allele' Mutation in the Human Peripherin/RDS Gene. Hum. Mol. Genet. 1993, 2, 2181-2182. [CrossRef]

39. Hoyng, C.B.; Heutink, P.; Testers, L.; Pinckers, A.; Deutman, A.F.; Oostra, B.A. Autosomal Dominant Central Areolar Choroidal Dystrophy Caused by a Mutation in Codon 142 in the Peripherin/RDS Gene. Am. J. Ophthalmol. 1996, 121, 623-629. [CrossRef]

40. Testa, F.; Marini, V.; Rossi, S.; Interlandi, E.; Nesti, A.; Rinaldi, M.; Varano, M.; Garré, C.; Simonelli, F. A Novel Mutation in the RDS Gene in an Italian Family with Pattern Dystrophy. Br. J. Ophthalmol. 2005, 89, 1066-1068. [CrossRef]

41. Kohl, S.; Giddings, I.; Besch, D.; Apfelstedt-Sylla, E.; Zrenner, E.; Wissinger, B. The Role of the Peripherin/RDS Gene in Retinal Dystrophies. Acta Anat. 1998, 162, 75-84. [CrossRef]

42. Nakazawa, M.; Kikawa, E.; Chida, Y.; Wada, Y.; Shiono, T.; Tamai, M. Autosomal dominant cone-rod dystrophy associated with mutations in codon 244 (Asn244His) and codon 184 (Tyr184Ser) of the peripherin/RDS gene. Arch. Ophthalmol. 1996, 114, 72-78. [CrossRef] [PubMed]

43. Reeves, M.J.; Goetz, K.E.; Guan, B.; Ullah, E.; Blain, D.; Zein, W.M.; Tumminia, S.J.; Hufnagel, R.B. Genotype-phenotype associations in a large PRPH2-related retinopathy cohort. Hum. Mutat. 2020, 41, 1528-1539. [CrossRef]

44. Nakazawa, M.; Naoi, N.; Wada, Y.; Nakazaki, S.; Maruiwa, F.; Sawada, A.; Tamai, M. Autosomal dominant cone-rod dystrophy associated with a Val200Glu mutation of the peripherin/RDS gene. Retina 1996, 16, 405-410. [CrossRef] [PubMed]

45. Trujillo, M.J.; Martinez-Gimeno, M.; Giménez, A.; Lorda, I.; Bueno, J.; García-Sandoval, B.; Ramos, C.; Carballo, M.; Ayuso, C. Two Novel Mutations (Y141H; C214Y) and Previously Published Mutation (R142W) in the RDS-Peripherin Gene in Autosomal Dominant Macular Dystrophies in Spanish Families. Hum. Mutat. 2001, 17, 80. [CrossRef] 
46. Peeters, M.; Khan, M.; Rooijakkers, A.; Mulders, T.; Haer-Wigman, L.; Boon, C.J.F.; Klaver, C.C.W.; van den Born, L.I.; Hoyng, C.B.; Cremers, F.P.M.; et al. PRPH2 mutation update: In silico assessment of 245 reported and 7 novel variants in patients with retinal disease. Hum. Mutat. 2021. [CrossRef] [PubMed]

47. Boon, C.J.; van Schooneveld, M.J.; den Hollander, A.I.; van Lith-Verhoeven, J.J.C.; Zonneveld-Vrieling, M.N.; Theelen, T.; Cremers, F.P.M.; Hoyng, C.B.; Klevering, B.J. Mutations in the peripherin/RDS gene are an important cause of multifocal pattern dystrophy simulating STGD1/fundus flavimaculatus. Brit. J. Ophthalmol. 2007, 91, 1504-1511. [CrossRef]

48. Coco-Martin, R.M.; Sanchez-Tocino, H.T.; Desco, C.; Usategui-Martin, R.; Telleria, J.J. PRPH2-Related Retinal Diseases: Broadening the Clinical Spectrum and Describing a New Mutation. Genes 2020, 11, 773. [CrossRef] [PubMed]

49. Shankar, S.P.; Birch, D.G.; Ruiz, R.S.; Hughbanks-Wheaton, D.K.; Sullivan, L.S.; Bowne, S.J.; Stone, E.M.; Daiger, S.P. Founder Effect of a c.828+3A $>$ T Splice Site Mutation in Peripherin 2 (PRPH2) Causing Autosomal Dominant Retinal Dystrophies. JAMA Ophthalmol. 2015, 133, 511-517. [CrossRef]

50. Nakazawa, M.; Wada, Y.; Tamai, M. Macular dystrophy associated with monogenic Arg172Trp mutation of the peripherin/RDS gene in a Japanese family. Retina 1995, 15, 518-523. [CrossRef]

51. Budu; Hayasaka, S.; Matsumoto, M.; Yamada, T.; Zhang, X.Y.; Hayasaka, Y. Peripherin/RDS gene mutation (Pro210Leu) and polymorphisms in Japanese patients with retinal dystrophies. Jpn. J. Ophthalmol. 2001, 45, 355-358. [CrossRef]

52. Fujiki, K.; Hotta, Y.; Hayakawa, M.; Fujimaki, T.; Takeda, M.; Isashiki, Y.; Ohba, N.; Kanai, A. Analysis of peripherin/RDS gene for Japanese retinal dystrophies. Jpn J. Ophthalmol. 1998, 42, 186-192. [CrossRef]

53. Yanagihashi, S.; Nakazawa, M.; Kurotaki, J.; Sato, M.; Miyagawa, Y.; Ohguro, H. Autosomal dominant central areolar choroidal dystrophy and a novel Arg195Leu mutation in the peripherin/RDS gene. Arch. Ophthalmol. 2003, 121, 1458-1461. [CrossRef]

54. Nakazawa, M.; Kikawa, E.; Kamio, K.; Chida, Y.; Shiono, T.; Tamai, M. Ocular findings in patients with autosomal dominant retinitis pigmentosa and transversion mutation in codon 244 (Asn244Lys) of the peripherin/RDS gene. Arch. Ophthalmol. 1994, 112, 1567-1573. [CrossRef]

55. Nakazawa, M.; Kikawa, E.; Chida, Y.; Tamai, M. Asn244His mutation of the peripherin/RDS gene causing autosomal dominant cone-rod degeneration. Hum. Mol. Genet. 1994, 3, 1195-1196. [CrossRef] [PubMed]

56. Kikawa, E.; Nakazawa, M.; Chida, Y.; Shiono, T.; Tamai, M. A novel mutation (Asn244Lys) in the peripherin/RDS gene causing autosomal dominant retinitis pigmentosa associated with bull's-eye maculopathy detected by nonradioisotopic SSCP. Genomics 1994, 20, 137-139. [CrossRef] [PubMed]

57. Saga, M.; Mashima, Y.; Akeo, K.; Oguchi, Y.; Kudoh, J.; Shimizu, N. A novel Cys-214-Ser mutation in the peripherin/RDS gene in a Japanese family with autosomal dominant retinitis pigmentosa. Hum. Genet. 1993, 92, 519-521. [CrossRef]

58. Gocho, K.; Akeo, K.; Itoh, N.; Kameya, S.; Hayashi, T.; Katagiri, S.; Gekka, T.; Ohkuma, Y.; Tsuneoka, H.; Takahashi, H. HighResolution Adaptive Optics Retinal Image Analysis at Early Stage Central Areolar Choroidal Dystrophy With PRPH2 Mutation. Ophthalmic Surg. Lasers Imaging Retin. 2016, 47, 1115-1126. [CrossRef]

59. Marano, F.; Deutman, A.F.; Leys, A.; Aandekerk, A.L. Hereditary retinal dystrophies and choroidal neovascularization. Graefes Arch. Clin. Exp. Ophthalmol. 2000, 238, 760-764. [CrossRef]

60. Conley, S.M.; Naash, M.I. Gene therapy for PRPH2-associated ocular disease: Challenges and prospects. Cold Spring Harb Perspect. Med. 2014, 4, a017376. [CrossRef] [PubMed]

61. Falfoul, Y.; Matri, K.E.; Habibi, I.; Halouani, S.; Chebil, A.; Schorderet, D.; El Matri, L. OCT-angiography assessing quiescent and active choroidal neovascularization in retinitis pigmentosa associated with PRPH2 pathogenic variant. Eur J. Ophthalmol. 2021. [CrossRef] [PubMed] 